\title{
PATIENTS WITH MALE GENDER OR GREATER BODY WEIGHT USE SMALLER AMOUNTS OF TOPICAL THERAPY IN PSORIASIS
}

\author{
RUNNING HEADER: TOPICAL THERAPY IN PSORIASIS \\ WORD COUNT: 669 \\ TABLE COUNT: 1 \\ FIGURE COUNT: 0
}

Minna E $\underline{\text { Kubin }}^{1}$, Tero J W $\underline{\text { Pääkkö }}^{2}$, Päivi M $\underline{\text { Hägg }}^{1}$, Kaisa Tasanen ${ }^{1}$ and Riitta Palatsi ${ }^{1}$.

1PEDEGO Research Unit, Oulu Center for Cell-Matrix Research, Department of Dermatology and Medical Research Center Oulu, Oulu University Hospital and University of Oulu, FIN-90220, Oulu, Finland

${ }^{2}$ Research Unit of Internal Medicine, Medical Research Center Oulu, Oulu University Hospital and University of Oulu, FIN-90220, Oulu, Finland

\section{Corresponding author:}

Minna Kubin

Department of Dermatology, Oulu University Hospital

Kajaanintie 50

90029 Oulu, Finland

e-mail: minna.kubin@ppshp.fi

Tel: +35883153508

fax: +35883153801 
FUNDING: None

DISCLOSURES: The authors have declared no conflicts of interest.

KEY WORDS: psoriasis, calcipotriol, betamethasone

\begin{abstract}
Topical therapy is the first-line of treatment in mild and moderate psoriasis. We performed a real-life study on topical therapies in psoriasis and observed a variation in the amounts of ointment patients applied during the study. A statistically significant correlation was found between gender and the total amount of ointment used: women used more than men $(\mathrm{p}=0.020)$. Also, heavier patients tended to use less ointment $(\mathrm{p}=0.038)$. We look forward to seeing whether the current pressure to improve psoriasis treatment leads to more patients receiving systemic therapies or to better adherence to, and persistence with, topical therapies.
\end{abstract}


The majority of psoriatic patients have mild skin symptoms and are treated with topical therapies only (1). The first-line of topical therapy for psoriasis treatment is generally calcipotriol, corticosteroids, or a combination of both (1). However, it is often observed in clinical practice that dermatologic patients tend to use smaller amounts of topical preparations than prescribed and psoriatic patients in particular have poor adherence to topical therapy (2). We performed a real-life study on topical therapies in psoriasis and observed, as an additional information, an interesting variation in the amount of ointment that was applied during the study.

Ten patients (Table 1) with mild or moderate psoriasis were randomly assigned to use betamethasone valerate ointment $(1 \mathrm{mg} / \mathrm{g}$ [0.1\%]; Bemetson®; Orion Pharma, Espoo, Finland; $\mathrm{n}=5)$ or betamethasone dipropionate and calcipotriol combination ointment $(50 \mu \mathrm{g} / \mathrm{g}$ calcipotriol and $0.5 \mathrm{mg} / \mathrm{g}$ [0.05\%] betamethasone; Daivobet ${ }^{\circledR}$; Leo Pharma, Vantaa, Finland; $n=5$ ) once a day after a shower over a period of one week (3). The ointments were given free of charge in non-blinded tube; no minimum dosages were recommended, but the maximum dosage was $100 \mathrm{~g}$ per week. The tubes were weighed before and after the study period. Demographic data collected included sex and body weight, and the severity of psoriasis was assessed using the Psoriasis Area and Severity Index (PASI) score (4) (Table 1). IBM SPSS Statistics 22.0 (IBM, Chicago, IL) software was used to conduct statistical analyses. Spearman's rho and analysis of variance were used to analyse correlations between the variables.

Even in this small cohort, a statistically significant correlation was found between gender and the total amount of ointment used: women used more than men $(\mathrm{p}=0.020)$. This finding could not be explained by a difference between men and women in psoriasis severity (mean \pm SD PASI score was: 10.2 \pm 2.9 in women and $8.0 \pm 2.8$ in men; $\mathrm{p}=0.244$ ). Our result is in line with previous studies which have demonstrated that women have better adherence to topical treatment than men $(5,6)$. Body weight was also associated with the total amount of ointment used: heavier patients tended to use less ointment 
$(\mathrm{p}=0.038)$, but there was no connection between patients' BMI score and the amount of ointment they used. The sex difference in ointment use mirrored the weight difference, since the male patients tended to be heavier than the females $(\mathrm{p}=0.401)$. As expected, the baseline PASI score correlated with the total amount of ointment used $(\mathrm{p}=0.038)$. No statistically significant correlations between any other variables were found.

The total amount of used ointment varied between $7.6 \mathrm{~g}$ and $73.3 \mathrm{~g}$ (median $24.15 \mathrm{~g}$ ) per week. The median amounts of used ointment did not markedly differ between the two therapies ( $24.9 \mathrm{~g}$ and $23.4 \mathrm{~g}$ of Bemetson ${ }^{\circledR}$ and Daivobet ${ }^{\circledR}$, respectively). Even though the total amount of ointment used was surprisingly low, PASI scores decreased as soon as one week after therapy initiation. The limited use of corticosteroid based topical therapies in our study might be a consequence of "steroid phobia", a fear frequently described among patients with atopic dermatitis (7) and psoriasis (8). We also speculate that patients with psoriasis are generally accustomed to using ointments, especially Daivobet ${ }^{\circledR}$, sparingly, due to their high cost.

If topical therapy for psoriasis fails, current guidelines recommend starting phototherapy or systemic therapy (1). This study raises a question as to whether some patients who receive these second-line treatment modalities could be effectively managed with properly administrated topical therapy only. From Jan $1^{\text {st }}, 2017$ all medications prescribed in Finland, have been issued via electronic prescriptions. All prescriptions and associated dispensing records are entered into a centralised database by pharmacies. This provides a tool when assessing the outcome of the therapy: the physician is able to track each patient's prescriptions and whether they are dispensed or not. However, any case of poor treatment adherence is a delicate issue to raise with the patient. We look forward to seeing whether the current pressure to improve psoriasis treatment leads to more patients receiving systemic therapies or to better adherence to, and persistence with, topical therapies. 


\section{REFERENCES}

1. American Academy of Dermatology Work Group, Menter A, Korman NJ, Elmets CA, Feldman SR, Gelfand JM, et al. Guidelines of care for the management of psoriasis and psoriatic arthritis: Section 6. guidelines of care for the treatment of psoriasis and psoriatic arthritis: Case-based presentations and evidence-based conclusions. J Am Acad Dermatol. 2011 Jul;65(1):137-74.

2. Devaux S, Castela A, Archier E, Gallini A, Joly P, Misery L, et al. Adherence to topical treatment in psoriasis: A systematic literature review. J Eur Acad Dermatol Venereol. 2012 May; 26 Suppl 3:61-7.

3. Kubin ME, Kokkonen N, Palatsi R, Hägg PM, Väyrynen JP, Glumoff V, et al. Clinical efficiency of topical calcipotriol/betamethasone treatment in psoriasis relies on suppression of the inflammatory TNFalpha - IL-23 - IL-17 axis. Acta Derm Venereol. 2017Apr 6;97(4):449-455.

4. Schmitt J, Wozel G. The psoriasis area and severity index is the adequate criterion to define severity in chronic plaque-type psoriasis. Dermatology. 2005; 210(3):194-9.

5. Carroll CL, Feldman SR, Camacho FT, Manuel JC, Balkrishnan R. Adherence to topical therapy decreases during the course of an 8-week psoriasis clinical trial: Commonly used methods of measuring adherence to topical therapy overestimate actual use. J Am Acad Dermatol. 2004 Aug; 51(2):212-6.

6. Zaghloul SS, Goodfield MJ. Objective assessment of compliance with psoriasis treatment. Arch Dermatol. 2004 Apr; 140(4):408-14.

7. Aubert-Wastiaux H, Moret L, Le Rhun A, Fontenoy AM, Nguyen JM, Leux C, et al. Topical corticosteroid phobia in atopic dermatitis: A study of its nature, origins and frequency. Br J Dermatol. 2011 Oct; 165(4):808-14. 
8. Brown KK, Rehmus WE, Kimball AB. Determining the relative importance of patient motivations for nonadherence to topical corticosteroid therapy in psoriasis. J Am Acad Dermatol. 2006 Oct; 55(4):607-13.

Table 1. Patient characteristics and amount of ointment used.

\begin{tabular}{|c|c|c|c|c|c|}
\hline Treatment & $\begin{array}{l}\text { Age/Gender } \\
(\mathrm{F} / \mathrm{M})\end{array}$ & $\begin{array}{l}\text { Weight }(\mathrm{kg}) / \\
\text { BMI }\end{array}$ & $\begin{array}{l}\text { PASI score } \\
\text { before }\end{array}$ & $\begin{array}{l}\text { PASI } \\
\text { score } \\
\text { after }\end{array}$ & $\begin{array}{l}\text { Total amount of } \\
\text { ointment used } \\
\text { (g) }\end{array}$ \\
\hline Bemetson $®$ & $25 / \mathrm{M}$ & $64 / 23.8$ & 12.6 & 8.4 & 24.9 \\
\hline Bemetson & $55 / \mathrm{M}$ & $76.5 / 26.5$ & 6.5 & 4.3 & 9.4 \\
\hline Bemetson & $55 / \mathrm{F}$ & $95 / 39.5$ & 10.5 & 9.9 & 27.9 \\
\hline Bemetson & $24 / \mathrm{M}$ & $100 / 34.4$ & 8.5 & 6.4 & 7.6 \\
\hline Bemetson & $34 / \mathrm{F}$ & $46 / 18$ & 8.6 & 8.4 & 38 \\
\hline Daivobet ${ }^{\circledR}$ & $52 / \mathrm{F}$ & $81.4 / 31.4$ & 6.4 & 3.6 & 23.4 \\
\hline Daivobet & $56 / \mathrm{F}$ & $55 / 19$ & 13.8 & 8 & 73.3 \\
\hline Daivobet & $38 / \mathrm{M}$ & $73 / 21.9$ & 7 & 5.2 & 9.3 \\
\hline Daivobet & $34 / \mathrm{M}$ & $79.1 / 25$ & 5.4 & 3.6 & 14.7 \\
\hline Daivobet & $57 / \mathrm{F}$ & $68 / 24$ & 12 & 9.3 & 37.7 \\
\hline
\end{tabular}

BMI: Body Mass Index; PASI: Psoriasis Area and Severity Index. 